\title{
EQUIPE TÉCNICA TEMPORÁRIA ESPECIALIZADA EM HOSPITAIS DE PEQUENO PORTE: ESTRATÉGIA DE CONTROLE DA COVID-19
}

Francisco Glauber Peixoto Ferreira https://orcid.org/0000-0002-3980-7253

Objetivo: traçar uma estratégia por meio da criação das Equipes Técnicas Temporárias Especializadas, a ser implementadas em hospitais de pequeno porte no atendimento aos casos com suspeita de infecção por COVID-19. Método: trata-se de um estudo de inovação tecnológica desenvolvido na relação entre a situação de calamidade pública mundial e as possibilidades pautadas na literatura. Realizou-se um levantamento bibliográfico na Biblioteca Virtual em saúde, ao final da pesquisa, elaborou-se como instrumento norteador um fluxograma em que consta o direcionamento para implementação dessa estratégia, e uma tabela dinâmica adaptável construída em eixos. Resultados: busca-se com esse projeto, desenvolver tecnologias rápidas e instantâneas no atendimento de enfermagem dentro de hospitais de pequeno porte, como também, orientar profissionais na conduta de pacientes suspeitos de Corona Virus. Na mesma ótica, desperta o interesse da classe para aquisição de uma visão mais crítica no setor de trabalho, através da adaptação fortalece os vínculos da administração com os membros assistencialistas. Considerações finais: A Equipe Técnica Temporária Especializada foi formulada com base em uma necessidade emergente em periodo de pandemia, em razão do grande número de casos suspeitos atendidos em hospitais interioranos, garantindo a segurança profissional.

Descritores: Tecnologias de Enfermagem; Método Organizacional; Pandemia; COVID-19.

\section{SPECIALIZED TEMPORARY TECHNICAL TEAM IN SMALL HOSPITALS: COVID-19 CONTROL STRATEGY}

Objective: outline a strategy through the creation of Temporary Specialized Technical Teams, to be implemented in small hospitals to assist cases with suspected COVID-19 infection. Method: it is a study of technological innovation developed in the relationship between the situation of global public calamity and the possibilities based on the literature. A bibliographic survey was carried out at the Virtual Health Library, at the end of the research, a flowchart was drawn up as a guiding instrument containing the direction for implementing this strategy, and an adaptable dynamic table built on axes. Results: this project seeks to develop rapid and instantaneous technologies in nursing care within small hospitals, as well as to guide professionals in the management of suspected Corona virus patients. In the same perspective, it arouses the interest of the class to acquire a more critical view in the work sector, through adaptation it strengthens the bonds of the administration with the assistentialist members. Final Considerations: the Temporary Specialized Technical Team was formulated based on an emerging need in a pandemic period, due to the large number of suspected cases treated in rural hospitals, guaranteeing professional safety.

Descriptors: Nursing Technologies; Organizational Method; Pandemic; COVID-19.

\section{EQUIPO TÉCNICO TEMPORAL ESPECIALIZADO EN PEQUEÑOS HOSPITALES: ESTRATEGIA DE CONTROL COVID-19}

Objetivo: esbozar una estrategia a través de la creación de equipos técnicos especializados temporales, que se implementarán en pequeños hospitales para ayudar a casos con sospecha de infección por COVID-19. Método: es un estudio de innovación tecnológica desarrollado en la relación entre la situación de calamidad pública global y las posibilidades basadas en la literatura. Se realizó una encuesta bibliográfica en la Biblioteca Virtual de Salud, al final de la investigación, se elaboró un diagrama de flujo como instrumento guía que contiene la dirección para implementar esta estrategia, y una tabla dinámica adaptable construida sobre ejes. Resultados: este proyecto busca desarrollar tecnologías rápidas e instantáneas en la atención de enfermería en pequeños hospitales, así como orientar a los profesionales en el manejo de pacientes sospechosos del virus Corona. En la misma perspectiva, despierta el interés de la clase de adquirir una visión más crítica en el sector laboral, a través de la adaptación fortalece los lazos de la administración con los miembros asistenciales. Consideraciones Finales: el Equipo Técnico Especializado Temporal fue formulado en base a una necesidad emergente en un período de pandemia, debido a la gran cantidad de casos sospechosos tratados en hospitales rurales, garantizando la seguridad profesional.

Descriptores: Tecnologías de Enfermería; Método Organizacional; Pandemia; COVID-19.

IUniversidade da Integração Internacional da Lusofonia Afro-Brasileira - UNILAB, CE.

Autor correspondente: Francisco Glauber Peixoto Ferreira. E-mail: fgpf.glauber@hotmail.com

Recebido:21/4/2020

Aceito: $01 / 6 / 2020$ 


\section{INTRODUÇÃO}

A falta de um direcionamento na realização da assistência tende a ocasionar na equipe de enfermagem situações de desconforto e insegurança, principalmente em períodos de pandemia, uma vez que se trata de um evento esporádico e instantâneo, fora das medidas de controle existentes nos sistemas mundiais de saúde. Diante dos fatos, a realidade vivenciada acontece concomitantemente com a realização de estudos envolvendo a temática.

De acordo coma Secretaria de Saúde do Estado do Ceará(1), o quantitativo de casos já se encontra dentro de parâmetros significativos, com um potencial de aumento em caráter exponencial de suspeitos e confirmados, principalmente na capital. Nesse sentido, as unidades hospitalares tendem a superlotação, com sobrecargas dos sistemas e serviços. Por outro lado, em cidades interioranas a ocorrência de afetados também se torna comum, por se tratar de um problema generalizado.

É imprescindivel insistir no fato de que o Brasil e o mundo passam por uma situação bastante delicada, uma vez que medidas instantâneas e eficazes são necessárias a serem implementadas em caráter de urgência. Desse modo, intervenções são primordiais nos cenários de saúde(2), que por sua vez entram em vários contextos, inclusive nas medidas de biossegurança de âmbito comunitário em prol do enfrentamento da COVID-19.

Em continuidade ao raciocínio, é inevitável que o profissional de enfermagem também se depare com o sofrimento do outro, principalmente quando nos referimos ao setor hospitalar de primeiros socorros ${ }^{(3)}$. Dessa forma, focar em quem presta assistência se torna um marco em meio a pandemia, de maneira que a prestação de cuidados seja realizada de forma integra para ambas as partes.

Diante dos fatos, a construção de instrumentos e tecnologias de enfermagem norteia o que podemos denominar de progresso assistencial, a medida em que torna a profissão mais concisa por meio da implementação de ferramentas padronizadas ${ }^{(4)}$. Para tanto, no atual cenário, essas inovações devem abranger o maior número de setores possíveis, além de apresentar resultados rápidos e consolidados na prática.

Em contrapartida, a atuação da Enfermagem por meio de equipe funciona de forma sincronizada, para se alcançar determinados objetivos do decorrer do atendimento prioritário a pacientes com potenciais riscos ${ }^{(5)}$. Esse tipo de organização fará parte da rotina de qualquer instituição de saúde durante a pandemia, pois em virtude da falta de compreensão a respeito da doença e uma capacitação inadequada poderá implica diretamente em um serviço desqualificado em meio à crise.

Nessa perspectiva, conforme a necessidade atual nas entidades de saúde, o presente trabalho surge como uma proposta inovadora com foco na proteção de profissionais que atuam em pequenos hospitais dentro do processo de acolhimento, manuseio, contenção e isolamento de pacientes que apresentam sintomatologia suspeita do vírus COVID-19. Portanto, em razão da ocorrência generalizada de casos, a proposta é enfatizar a adequação e consequentemente a singularidade de cada funcionamento ou instituição.

\section{Objetivo}

Diante do exposto, o objetivo desse estudo foi traçar uma estratégia por meio da criação das Equipes Técnicas Temporárias Especializadas, denominada de ETTE, a ser implementada em hospitais de pequeno porte no atendimento aos casos com suspeita de infecção por COVID-19.

\section{MÉTODO}

Trata-se de um estudo de inovação tecnológica desenvolvido na relação entre a situação de calamidade pública mundial e as possibilidades pautadas na literatura. Mediante o exposto, a construção da pesquisa seguiu um protocolo continuo por meio de etapas, no qual se pode estabelecer um percurso metodológico mais conciso. A primeira etapa baseou-se na realização de um levantamento bibliográfico na Biblioteca Virtual em saúde (BVS), direcionado para as seguintes bases de dados: Scientific Eletronic Library Online (Scielo), Literatura LatinoAmericana e do Caribe em Ciências da Saúde (Lilacs) e Literatura Internacional em Ciências da Saúde (Medline). Para isso, utilizou-se os seguintes descritores: "tecnologias de enfermagem", "pandemias" e "COVID-19".

A segunda etapa consistiu na seleção desses periódicos com base na temática abordada, utilizando como ponto norteador as tecnologias e os recursos de caráter instantâneo no controle e contenção da disseminação do Corona Vírus. Em seguida optou-se por realizar um fichamento no intuito de coletar as informações mais relevantes para o direcionamento da elaboração. A terceira e última etapa foi construir um conceito, nesse caso, a estratégia ETTE, baseado nas situações e necessidades vivenciadas nos cenários de saúde em hospitais interioranos, especificamente no atendimento a pacientes suspeitos.

Em outras palavras, o arsenal teórico teve por objetivo promover uma abordagem qualitativa, evidenciando a interpretação e análise dos elementos obtido por meio da pesquisa bibliográfica $a^{(6)}$. Por conseguinte, a construção desse artigo promoveu acima de tudo uma aproximação no paradoxo teoria-prática, cujo processo baseia-se na sistematização de informações sobre questão especificas, em que atinge por consequência um objeto de conhecimento através das afirmações obtidas ${ }^{(7)}$. 
A partir do apanhado, foi perceptivel uma escassez quanto a produção científica de estratégias ou tecnologias de enfermagem voltadas para situações pandêmicas. Com isso, optou-se por focar em referências que atendessem a construção de instrumentos de fácil execução, como é o caso da recomendada por Pimenta, Lopes, Amorim, Nishi, Shimoda, Jensen8. Nesse quesito, sua principal relevância baseia-se na elaboração de protocolos clínicos de acordo com as orientações do Conselho Federal de Enfermagem (Cofen) ${ }^{(9)}$, que trata da adaptação de enfermagem nos diversos âmbitos. Além disso, apresenta informações completas e concisas em atender as necessidades da problemática em questão.

O autor estabelece que, para a elaboração de protocolos de enfermagem é necessário seguir uma sequência de doze passos baseados na origem; objetivo; grupo de desenvolvimento; conflito de interesse; evidências; revisão; fluxograma; indicador de resultados; validação profissional, validação dos usuários; limitação e plano de implantação. Contudo, esse estudo se limitou aos seis primeiros passos, uma vez que, o principal intuito foi apenas a construção da estratégia.

Ao final da pesquisa, elaborou-se como instrumento norteador um fluxograma em que consta o direcionamento para implementação da ETTE, além de uma tabela dinâmica adaptável construida em eixos, em que apresenta dois subtópicos no objetivo de facilitar a compreensão, que são basicamente: recomendações e justificativas.

Por se tratar de uma produção de urgência conforme demanda, não foi possível realizar a etapa de validação, visto que exige um tempo considerável e a participação de especialistas na área de tecnologia de enfermagem. Todavia, cogita-se a possibilidade de realizar esse procedimento em um futuro próximo e oportuno, inclusive relacionado também aos aspectos éticos.

\section{OBJETIVOS DA INOVAÇÃO}

O objetivo geral da presente inovação consiste em implementar um plano dinâmico e de fácil execução em hospitais de baixa complexidade através de uma Equipe Técnica Temporária Especializada, ou seja, integrantes que passarão por um treinamento intensivo e específico com fins de atuação por um tempo determinado, primordialmente em casos de atendimento a suspeitos de infecção por COVID-19. Por outro lado, pretende-se reduzir o contato desnecessário dos demais profissionais atuantes nessas unidades após o funcionamento da ETTE, com início do momento de acolhimento até o desfecho clínico.

Outro ponto de abordagem seria conter os casos em investigação na própria instituição, de maneira que a ETTE possa prestar uma assistência segura a esses indivíduos durante a internação, de modo a evitar qualquer aproximação com familiares, vizinhos e amigos no isolamento domiciliar. Nessa constatação, a estratégia também permite preservar a saúde profissional, pois direciona para um cuidado sistematizado, amenizando o desgaste físico e mental dos que atuam diretamente na linha de frente nos casos de pandemia.

\section{DESCRIÇÃO DA INOVAÇÃO}

O presente estudo se baseia em uma tecnologia de enfermagem por meio da criação da ETTE em hospitais de pequeno porte das cidades interioranas. Por isso, o projeto segue um fluxo para sua execução, de maneira que as orientações sirvam para nortear o gerenciamento de enfermagem ou direção clínica.

Primeiramente buscou-se estabelecer algumas recomendações que servirão como molde para uma adaptação mais eficaz baseada no funcionamento singular de cada instituição. Para isso, a ETTE deverá ser comandada por um instrutor, no qual recomenda-se a chefia de enfermagem ou direção clínica hospitalar. No que tange ao método organizacional, este pode sofrer modificação desde que não estejam em contradição com o que está preconizado em protocolo pelo Ministério da Saúde (MS) na respetiva temática de pandemia pela COVID-19 quanto a conduta, coleta, resultados e manejo de casos.

Nessa ótica, pode ser observado na figura 1 uma ordem lógica e continua, que se inicia pela indicação de um instrutor quetem pormissão: organizarumambienteao qualfuncionará como quartos de isolamentos; convocar integrantes que irão compor as equipes; fornecer a preparação necessária de atuação baseada em um treinamento intensivo; realizar uma simulação de teste como processo de avaliação de desempenho e; estabelecer as normas para o funcionamento correto conforme o presente plano.

Figura 1 - Esquematização de fluxo para implementação da Equipe Técnica Temporária Especializada.

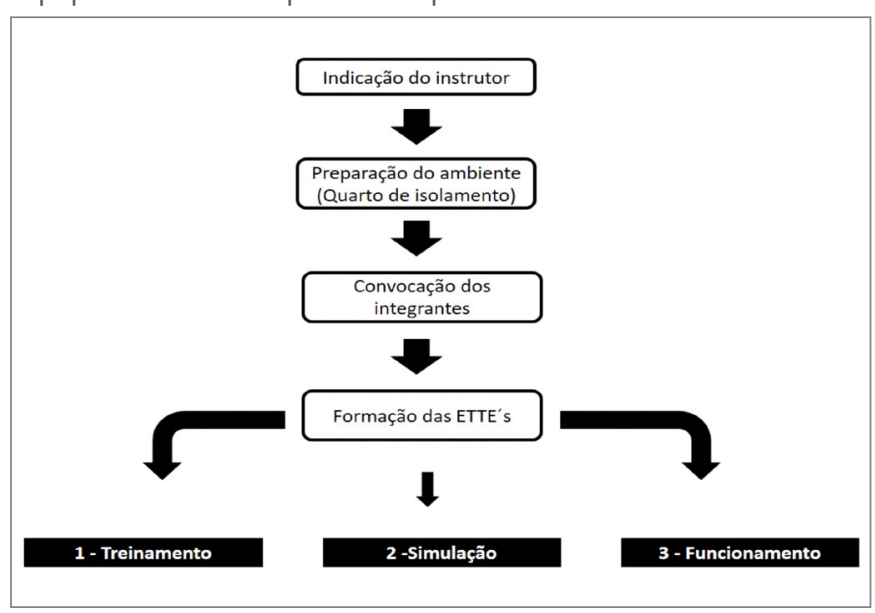

Enferm. Foco 2020; 11 (1) Especial: 211-216 
Após uma visão geral do esquema de planejamento e implementação, procurou-se detalhar com base em eixos, que como demonstrado na Tabela 1 segue na seguinte ordem: eixol - Ambiente: compreende as normas de conduta na preparação do ambiente, ou seja, nos quartos de isolamentos; já o eixo 2 - Formação da ETTE: trata-se dos preceitos de formação das equipes, de maneira organizada a minimizar qualquer tipo de falha ou desfalques; o eixo 3 - Treinamento: remete-se basicamente a preparação necessária que as equipes deverão se submeter para atuar de forma efetiva e com boa produtividade; e por último e não menos importante lista-se no eixo 4 - Funcionamento: considerado o ponto mais importante quando se trata de aspecto prático, em que consta as instruções de como proceder.

Nesse contexto, como observado no decorrer da leitura a ETTE traz como proposta principal a adaptabilidade para que cada hospital possa utilizá-la de acordo com suas limitações e necessidades, em que as alterações realizadas nos determinados eixos seguirão conforme rotina institucional de âmbito singular. Para isso, a Tabela 1 abaixo segue como um modelo molde, ao qual teve por referência a maioria das unidades de pequeno porte existente no interior do Ceará, na qual funciona como alicerce para as inúmeras variedades de equipes que poderão atuar em diferentes contextos e situações.

Referindo-se a parte conceitual aqui apresentada, os periódicos e protocolos foram submetidos a uma análise mais detalhada para construção da Tabela-Eixo, pois houve todo um direcionamento para a realidade da atenção secundária de baixa complexidade, como objetivo foco para o encaixamento da ETTE. Com relação ao ambiente, utilizouse as informações explanadas por Bortoluzzi, Cavalcante, Ely ${ }^{(10)}$, por se tratar de uma literatura recente que aborda especificamente os protocolos estruturais de um quarto de isolamento. Para a formação da equipe, a referência base foi o Manual Prático - Dimensionamento de Pessoal Resolução Cofen no 543/2017(11). Já as recomendações de treinamento e funcionamento foram pautadas na Cartilha de Procedimento Operacional Padronizado ${ }^{(12)}$.

Tabela 1 - Eixos direcionadores de implementação da Equipe Técnica Temporária Especializada.

\begin{tabular}{|c|c|}
\hline \multicolumn{2}{|c|}{ EIXO 1 - AMBIENTE } \\
\hline RECOMENDAÇÃO & JUSTIFICATIVA \\
\hline $\begin{array}{l}\text { 1. Recomenda-se um } \\
\text { quantitativo de no mínimo } 2 \\
\text { quartos de isolamento com seus } \\
\text { devidos sanitários. }\end{array}$ & $\begin{array}{l}\text { 1.1. Evitar junção } \\
\text { de } 2 \text { pacientes } \\
\text { suspeitos que } \\
\text { apresentem mesma } \\
\text { sintomatologia. }\end{array}$ \\
\hline
\end{tabular}

\begin{tabular}{|c|c|}
\hline $\begin{array}{l}\text { 2. Os quartos devem ser } \\
\text { equipados com cama, porta } \\
\text { roupas, mesa de maio e itens de } \\
\text { higiene pessoal. }\end{array}$ & $\begin{array}{l}\text { 2.1. Proporcionar } \\
\text { conforto e assegurar } \\
\text { a segurança para os } \\
\text { pertences do paciente. }\end{array}$ \\
\hline $\begin{array}{l}\text { 3. A localização dos quartos } \\
\text { deve possuir um distanciamento } \\
\text { considerável dos demais setores } \\
\text { de atendimento. }\end{array}$ & $\begin{array}{l}\text { 3.1. Preservar os } \\
\text { demais pacientes } \\
\text { do contato em } \\
\text { internamento por } \\
\text { causas distintas. }\end{array}$ \\
\hline $\begin{array}{l}\text { 4. Adequar o espaço com boa } \\
\text { ventilação, de preferência } \\
\text { climatização por ar- } \\
\text { condicionado. }\end{array}$ & $\begin{array}{l}\text { 4.1. Delimitar } \\
\text { circulação de ar dos } \\
\text { pacientes suspeitos } \\
\text { em espaço delimitado. }\end{array}$ \\
\hline $\begin{array}{l}\text { 5. Promover uma maior } \\
\text { possibilidade de conforto } \\
\text { no ambiente de acordo com } \\
\text { os recursos e faixa etária. } \\
\text { (Exemplo: televisão, rádio, jogos } \\
\text { e brinquedos) }\end{array}$ & $\begin{array}{l}\text { 5.1. Dinamizar o } \\
\text { ambiente, evitando } \\
\text { ansiedade e tédio, } \\
\text { preservando a saúde } \\
\text { mental. }\end{array}$ \\
\hline \multicolumn{2}{|c|}{ EIXO 2 - FORMAÇÃO DA ETTE } \\
\hline RECOMENDAÇÃO & JUSTIFICATIVA \\
\hline $\begin{array}{l}\text { 1. Recomenda-se um } \\
\text { quantitativo de no mínimo } 2 \\
\text { quartos de isolamento com seus } \\
\text { devidos sanitários. }\end{array}$ & $\begin{array}{l}\text { 1.l. Evitar junção } \\
\text { de } 2 \text { pacientes } \\
\text { suspeitos que } \\
\text { apresentem mesma } \\
\text { sintomatologia. }\end{array}$ \\
\hline $\begin{array}{l}\text { 2. Os quartos devem ser } \\
\text { equipados com cama, porta } \\
\text { roupas, mesa de maio e itens de } \\
\text { higiene pessoal. }\end{array}$ & $\begin{array}{l}\text { 2.1. Proporcionar } \\
\text { conforto e assegurar } \\
\text { a segurança para os } \\
\text { pertences do paciente. }\end{array}$ \\
\hline $\begin{array}{l}\text { 3. A localização dos quartos } \\
\text { deve possuir um distanciamento } \\
\text { considerável dos demais setores } \\
\text { de atendimento. }\end{array}$ & $\begin{array}{l}\text { 3.1. Preservar os } \\
\text { demais pacientes } \\
\text { do contato em } \\
\text { internamento por } \\
\text { causas distintas. }\end{array}$ \\
\hline $\begin{array}{l}\text { 4. Adequar o espaço com boa } \\
\text { ventilação, de preferência } \\
\text { climatização por ar- } \\
\text { condicionado. }\end{array}$ & $\begin{array}{l}\text { 4.1. Delimitar } \\
\text { circulação de ar dos } \\
\text { pacientes suspeitos } \\
\text { em espaço delimitado. }\end{array}$ \\
\hline $\begin{array}{l}\text { 5. Promover uma maior } \\
\text { possibilidade de conforto } \\
\text { no ambiente de acordo com } \\
\text { os recursos e faixa etária. } \\
\text { (Exemplo: televisão, rádio, jogos } \\
\text { e brinquedos) }\end{array}$ & $\begin{array}{l}\text { 5.1. Dinamizar o } \\
\text { ambiente, evitando } \\
\text { ansiedade e tédio, } \\
\text { preservando a saúde } \\
\text { mental. }\end{array}$ \\
\hline
\end{tabular}




\section{EIXO 3 - TREINAMENTO}

1. O treinamento da ETTE deve ser realizado de forma intensiva e dinâmica.

2. Todos os integrantes devem obrigatoriamente passar pelo treinamento de forma conjunta em momento único.

3. As principais temáticas abordadas no treinamento devem envolver: biossegurança em saúde, boas práticas hospitalares, manejo e isolamento e recomendações do Ministério da Saúde de acordo com protocolo.

4. A simulação deve ser realizada ao final do processo de treinamento.

5. Refazer o treinamento a cada mudança de protocolo de acordo com o Ministério da Saúde.

EIXO 4 - FUNCIONAMENTO E ADAPTAÇÃO

1. O plantão de cada equipe deve seguir rotina institucional.

2. Em casos de imprevistos, o integrante substituto poderá assumir o posto. decisória final quanto as questões assistenciais.

4. A ETTE deve atuar unicamente na instituição ao qual foi convocada.

5. Após a triagem e confirmação de sintomatologia o atendente deverá direcionar o paciente direto para o ambiente de isolamento.
1.1. Otimizar o tempo de atuação e facilitar a compreensão.

2.1. Otimizar o tempo e implementação da estratégia.

\subsection{Direcionar} atendimento da ETTE de forma eficaz.

4.1. Avaliar preparação dos integrantes e corrigir possiveis falhas.

5.1. Promover adaptação das ETTE com bases nas novas mudanças.

1.1. Evitar sobrecarga de trabalho.

2.1. Evitar desfalque da equipe.

3.1. Na maioria dos hospitais de pequeno porte, apenas 1 enfermeiro assume diversos setores.

4.1. Evitar sobrecarga de trabalho.

5.1. Facilitar a realização dos protocolos do Ministério da Saúde.
A tabela anterior não se remete a um protocolo padrão acabado, funciona como modelo com 5 exemplos para que os possiveis instrutores possam utiliza-la em relação as particularidades de seus hospitais de atuação. Para tanto, recomenda-se aos mesmos recorrer a literatura indicada no início do tópico para um aprofundamento em cada eixo e aquisição de conhecimento para formular suas próprias recomendações e justificativas.

\section{RESULTADOS}

Busca-se com esse projeto, desenvolver tecnologias rápidas e instantâneas no atendimento de enfermagem dentro de pequenos hospitais através da ETTE, como também, orientar profissionais na conduta de pacientes suspeitos de Corona Vírus. Além disso, o estudo abre caminhos para o surgimento de novas pesquisas em áreas afins, priorizando medidas de controle da propagação viral.

Acrescenta-se a isso, o objetivo de despertar o interesse da classe para aquisição de uma visão mais crítica no setor de trabalho, que por meio da adaptação fortalece os vínculos da administração com a equipe assistencial. Nesse quesito, o produto final remete-se a uma assistência segura e padronizada, que permite uma tomada de decisão consolidada de acordo com normas orientadoras préestabelecidas.

\section{Limites da inovação}

Uma das limitações da ETTE é com relação a sua validação, pelo motivo de que todo instrumento e tecnologia necessitam passar pela análise de especialistas na área, para seu posterior uso pautado em aprovação. No entanto, por se tratar de uma estratégia de fácil compreensão e executável em baixo custo financeiro, tende a se moldar adequadamente a diferentes intuições, dado que a demanda emergencial exige resultados rápidos e concretos.

\section{Contribuição para a prática}

Essa ideia permite acima de tudo, propor um método padronizado que garante a segurança profissional e manejo correto de pacientes suspeitos. Paralelamente, a ETTE possui fácil compreensão e execução, medidas extremamente essenciais durante esse periodo pandêmico, em que possibilita alternativas plausíveis e executáveis instantaneamente. Outra questão gira em torno do quesito adaptabilidade, em que se enquadra no uso universal, priorizando as particularidades da dinâmica de cada hospital a ser aplicada.

\section{CONSIDERAÇÕES FINAIS}

A ETTE foi formulada com base em uma necessidade 
emergente em período de pandemia, em razão do grande número de casos suspeitos atendidos em pequenas cidades. Salienta-se nesse caso, que as aplicações de tecnologias instantâneas são fundamentais nesse momento de crise, já que possibilita um notório aprimoramento na qualidade da assistência de enfermagem, priorizando o tempo de adequação e consequentemente a busca por resultados adequados.

Concomitantemente, abre caminhos para a criação de novas possibilidade que possam contribuir de forma segura no atendimento aos indivíduos afetados pela COVID-19. Posto que, as produções cientificas, sejam estas de base experimental ou epidemiológica, atuarão de maneira conjunta e integrada em prol da saúde e bemestar populacional, com ênfase em orientar profissionais e desenvolvendo tecnologias que possam contribuir na prestação de assistência acessivel e de qualidade.

CONTRIBUIÇÃO DOS AUTORES: O artigo foi construído em uma única autoria, cabendo ao mesmo a realização de elaboração, busca, interpretação dos dados, análise crítica, redação e revisão.

FINANCIAMENTO: Fundação Cearense de Apoio ao Desenvolvimento Científico e Tecnológico - FUNCAP

AGRADECIMENTOS: A Fundação Cearense de Apoio ao Desenvolvimento Científico e Tecnológico (FUNCAP) pelo incentivo na realização de estudos e apoio aos novos pesquisadores.

\section{REFERÊNCIAS}

1. Ceará. Secretaria da Saúde do Ceará. Doença pelo novo Coronavirus (COVID-19). Inf. Epidem. v.18, n.18, p.1-9. 2020 Disponivel em: < https://www.saude.ce.gov.br/download/arquivos-coronavirus-COVID-19/>. Acesso em: 01, abr. 2020

2. Qualls N, Levitt A, Kanade N, Wright-Jegede N, Dopson $\mathrm{S}$, Biggerstaff $\mathrm{M}$, et al. Community mitigation guidelines to prevent pandemic influenza - United States, 2017. MMWR Recomm Rep [Internet]. v.66, n.1, p.1-32, 2020. Available from: https://doi.org/10.15585/mmwr.rr660lal.

3. Miorin, JD, Camponogara S, Pinno C, Freitas EO, Cunha QB, Dias GL. Estratégias de defesa utilizadas por trabalhadores de enfermagem atuantes em pronto-socorro. Enferm. Foco, v.7, n.2, p.57-61, 2016. Disponivel em: < http://revista. cofen.gov.br/index.php/enfermagem/article/view/796> Acesso em: 01, abr. 2020

4. Felipe TRL, Spiri WC. Construção de um instrumento de passagem de plantão. Enferm. Foco, v.10, n.7, p.76-82, 2019 Disponivel em: < http://revista.cofen.gov.br/index.php/enfermagem/article/view/2451>. Acesso em: 01, abr. 2020.

5. Carvalho BC. Atuação da equipe de enfermagem no cuidado ao paciente grave. REAS/EJCH, v.17, n.36, p.1-7, 2019. Doi: https://doi.org/10.25248/reas36_2019

6. Minayo MCS. O desafio do conhecimento: pesquisa qualitativa em saúde. 9ạ ed. São Paulo: EDUC, 2006.

7. Lopes GT, organizador. Manual para elaboração de trabalhos acadêmicos: normas da ABNT - Estilo Vancouver Bioética. Rio de Janeiro: UERJ/EPUB, 2006.

8. Pimenta CAM, Lopes CT, Amorim AF, Nishi FA, Shimoda
GT, Jensen R. Guia para construção de protocolos assistenciais de enfermagem. São Paulo: COREN, 2017. Disponivel em: < https://portal.coren-sp.gov.br/sites/default/ files/Protocolo-web.pdf> Acesso em: 01 abr 2020.

9. Conselho Federal de Enfermagem (Cofen). Diretrizes para elaboração de protocolos de enfermagem na atenção primária à saúde pelos conselhos regionais. Brasil COFEN, 2018. Disponivel em: <http://www.cofen.gov.br/ wp-content/uploads/2019/03/Diretrizes-para elabora\%C3\%A7\%C3\%A3o-de-protocolos-de-Enfermagem-.pdf>. Acesso em: 16 mai 2020.

10. Bortoluzzi TVC, Cavalcanti PB, Ely VJMB. Quartos de isolamento em unidades de urgência e emergência: sinergia entre legislação e prática? Arquitetura Revista, v.16, n.1, 2020. Disponivel em: < http://www.revistas.unisinos.br/index.php/arquitetura/article/view/arq.2020.161.07>. Acesso em: 01, abr. 2020

11. Canavezi CM, Nicola AL, Marinho AM, Fugulin FT, Biehl JI. Sávia A. Conselho Federal de Enfermagem. Manual Prático: dimensionamento de pessoal. Resolução 543/2017. Disponivel em: < http://edimensionamento.cofen.gov.br/ anexos/MANUAL_PRATICO.pdf?cid=4314>. Acesso em: 01, abr. 2020

12. Ministério da Saúde (BR).Secretaria de Atenção Primária a Saúde. Procedimento Operacional Padronizado. Ministério da Saúde, Brasilia-DF. 2020. Disponivel em: < https:// portalarquivos.saude.gov.br/images/pdf/2020/marco/30/ 20200330-POP-EPI-verO02-Final.pdf>. Acesso em: 01, abr. 2020 